\title{
Human Resource Management practices that translate into sustainable competitive advantage
}

\section{Ewa BULAT}

\section{WSB University in Wroclaw, Poland}

\begin{abstract}
:
Aim: The aim of the paper is to delve into the Human Resource Management (HRM) practices which undoubtedly translate into enhanced business performance. The article combines the theoretical study of HRM with its application to professional practice in order to provide a comprehensive analysis of the reasons and ways of implementing good HRM processes.
\end{abstract}

Design/Research methods: A desk case study approach has been adopted to conduct a descriptivecomparative analysis of two prosperous corporations operating in distinct sectors.

Conclusions/findings: It is suggested that the analysed companies have been consistently outperforming their competitors due to their HRM practices which can be linked back to the seminal motivation theories and concepts relating HRM to performance. It seems that especially the application of AMO framework and Path-Goal Theory to workplace scenarios can yield good results, regardless of the industry.

Originality/value of the article: This study not only provides an insight into the HRM practices which appear to contribute most to improved productivity, but it also attempts to shed some light on the how and why of their application. So far, much of the empirical research has confirmed a significant statistical connection between HRM practices and business success, but relatively little attention has been paid to understanding the exact mechanisms through which conceptual HRM practices can be implemented. An attempt to address this gap is the value added of the paper.

Implications: The findings may prompt the upper echelons of power in companies to fit the appropriate HR practices into their business strategies to achieve the organisational objectives.

Keywords: human capital, talent management, motivation theories, non-cash incentives, training and development, sustainable competitive advantage

JEL: J24, M12, J28, J32, M53, L21

Contact details: Ewa Bułat, WSB University in Wrocłąw, ul. Fabryczna 29-31, 53-609 Wrocław, Poland. E-mail: ewa.butlat@wsb.wroclaw.pl Received: 23.09.2017, Revised: 10.04.2018, Revised: 01.05.2018 doi: http://dx.doi.org/10.29015/cerem.507 


\section{Introduction}

It goes without saying that every company needs a strategy. This is to make sure that an organisation can fulfil its mission, achieve its goals and maintain unity, which will enable it to continue into the future. In this sense, effective strategic management points the organisation in the right direction and ensures it remains on track. As pointed out by Patrick Schutz and Donald Carpenter (2008: 19), the quality of a company's strategic management, comprising processes of strategy formulation and implementation, will undeniably depend on the nature of human talent - at all levels - that the company is able to attract and retain. After all, an organisation is only as strong as its people. Following Rochelle Mucha (2004; qtd. in Schutz, Carpenter 2008: 20), ,the ability to execute business strategy is rooted in the ability to attract, retain, and develop key talent. Successful talent management creates the most enduring competitive advantage. No company can afford to be unprepared for both the best and worst of times". The way that talent is being managed directly determines whether the organisation is going to achieve its strategic objectives. Therefore, talent management is inseparably linked with strategic management. As Schutz and Carpenter (2008: 19) further observe, knowledge management processes also serve strategic management. This is because an organisation's human talent generates, obtains, and transfers knowledge used in strategy formulation and its implementation. That is why both talent and knowledge are often subsumed under the heading of human capital - the preeminent asset of any organisation. That human capital, i.e. the knowledge, skills, abilities, and talent of the employees, should be appropriately managed to add value to the company - again, a strategy is needed. I concur with Barry Colbert (2004) that „by organising human resource management processes around a set of coherent, mutually supporting principles, a firm has the potential to build a unique resourcebased advantage in its industry". Thus, by implementing the proper Human Resource Management (HRM) practices, the businesses could enhance their viability and economic performance - the ultimate goal of any organisation. 


\section{Research objectives and methodology}

This article scrutinises the HR practices which appear to contribute most to improved productivity and enduring competitive advantage. A case study approach has been adopted to perform a descriptive-comparative analysis of two prosperous companies operating in different industries. The research is based on industry reports, reviews and journals, company information (including employee survey results), white papers, newspaper articles, and interview transcripts. The analysis is preceded by a literature and theory overview to enable understanding of the concept of good HRM in a broader, more holistic context. The theoretical underpinnings of HRM 'best practices', combined with real-life examples of their implementation, will hopefully help management professionals understand why and how to apply their ideas for better HRM, while giving them freedom to use their professional judgement in designing bespoke 'good' practices for everyday workplace scenarios. As will be demonstrated later in this article, HRM practices can be implemented as part of a well-thought-out HR strategy, improving the company's efficiency and increasing its competitive advantage.

\section{Literature review}

A review of the literature reveals that although there is some fundamental agreement on the connection between HRM practices and company performance, there is a lack of understanding about the process through which HRM creates organisational value and increases performance (Becker, Gerhart 1996). Patrick Wright et al. (2003) point out that while much of the research has demonstrated statistically significant relationship between HRM practices and firm profitability, indicating the potential value triggered by them, very little has been revealed regarding the processes through which that value is created. John Purcell et al. (2003) also notice that many previous studies have examined the link between HRM practices and have shown there is a positive connection, but none has actually explained the nature of this connection, i.e. how and why HRM practices influence performance. This view 
seems to be compatible with that of Georgios Theriuo and Prodromos Chatzoglou's (2009), who argue that - despite the quantity and variety of empirical studies - little attention has been paid to the concept or understanding of the mechanisms through which HRM practices impact performance. According to Theriuo and Chatzoglou, there appears to be only a limited amount of research attempting to pinpoint the processes through which HRM practices can lead to competitive advantage.

Hopefully, this article is going to shed some light on the above-mentioned aspects, identifying HRM practices which should be introduced to assist the company in achieving its strategic objectives via utilising its human capital to its maximum potential. This entails discussion on the ways to retain talent within the organisation via motivating gifted employees to stay and perform their jobs to the best of their ability - since this is what, in turn, translates into sustainable competitive advantage.

As stated by Peggy De Prins (2011), if people are the centre of a sustainable competitive advantage, then the knowledge and fostering of what inspires and characterises them is of utmost importance, i.e. to put it simply, what motivates people to come to work, to develop expertise, and to become and stay productive. A review of the pertinent concepts below reveals that the theoretical underpinnings of good HRM rest on psychological mechanisms underlying our motivation to work. Yet, it seems that not many managers are cognisant of this fact. Therefore, in order to understand how HR best practices actually work, a broader, more holistic perspective is needed. For that reason, it is useful to take a look at the seminal theories on employee motivation.

\section{The seminal theories on employee motivation}

Most of the themes can be linked back to Abraham Maslow's Hierarchy of Needs - one of the most recognisable motivation theories. According to Maslow, there are five levels of personal needs: physiological needs, safety needs, love and belonging needs, self-esteem needs and self-actualization, or growth needs (Maslow 
1943). The theory argues that - in order to engage in work - people must satisfy lower-level needs before they can move on to satisfy higher-level ones.

Frederick Herzberg's Two-Factor Theory classified motivation into hygiene factors and motivational factors (so called „motivators"). Hygiene factors relate to the job environment, such as company policy, remuneration and working conditions, being potential sources of work dissatisfaction - but only if they are deficient. When appropriate, however, they do not necessarily encourage anyone to perform better. On the other hand, motivators, such as achievement, recognition, responsibility, and other personally rewarding factors may be used to increase productivity, but only when combined (Herzberg et al. 1959).

Douglas McGregor's X/Y Theory (McGregor 1960) presented a two-pronged approach: Theory $\mathrm{X}$ underlies most managers' thinking, whereas Theory $\mathrm{Y}$ proposes a set of assumptions for managers to concentrate on. Theory $\mathrm{X}$ emphasises physiological and safety needs and tends to ignore the higher-level needs in Maslow's ladder. It coincides with an authoritarian management style, claiming that the average person dislikes work, avoids it whenever possible, has little ambition, and so prefers to be directed rather than take on responsibility. In other words, Theory X-oriented managers believe workers must be forced to put forth enough effort to achieve the company's goals, and can be motivated only by fear of losing their jobs or by material rewards. Theory Y, conversely, argues that people enjoy working, seek responsibility, and want to excel at their jobs. Accordingly, the assumptions behind theory Y underscore growth and self-direction.

Last but not least, Robert House's (1971) Goal-Setting Theory focuses on managers as the critical factors in motivating workers. To attract, retain, and motivate high-flyers, managers must be clear, consistent, and reliable in communicating details on rewards for the achievement of goals. Managers should remove any contextual obstacles to achievement, such as personality conflicts within a team, role ambiguity or office politics, which are hindering employee development and continuous learning - especially important for consistent achievement. Robert House and Terence Mitchell (1974) in an extended Path-Goal Theory further depict the responsibility of a manager to appropriately motivate employees, especially those 
performing complex, expert or stressful jobs. They provide methods or ways through which the manager could achieve that, i.e. via:

- Considering the needs of the employee, showing concern for their welfare and creating a friendly working environment. This includes increasing the employee's self-esteem and making the job more interesting.

- Telling employees what needs to be done and giving appropriate guidance along the way.

- Consulting with employees and taking their ideas into account when making decisions and taking particular actions (esp. when employees are experts in the field, and so they expect to be able to give advice).

- Setting challenging goals, thus showing belief in the employee's capabilities and potential to succeed.

This theory seems to be particularly true, as recent studies indicate employees leave managers more than they leave companies. In other words, how you treat your people is how they will experience the organisation.

There are also theories linking HRM to performance. The ability, motivation and opportunity theory or AMO framework, for short, (Appelbaum et al. 2000) is probably the most popular theoretical concept associated with HRM systems (Jiang et al. 2012a), especially to test empirically the impact of HRM practices on business outcomes, such as higher organisational performance (e.g. Jiang et al. 2012b). The theory suggests that there are three independent work system components that shape employees characteristics and contribute to the success of the organisation. According to the theory, organisation's interests are best served by a system that attends to employee ability, motivation, and opportunity - or AMO. This can be achieved through increasing employees' Ability through attracting and developing high-performing employees; enhancing employees' Motivation and commitment through practices such as contingent rewards and effective performance management; and providing employees with the Opportunity to engage in the decision-making process or challenging problem-solving activities. If any one of the three characteristics is missing, performance is likely to be inhibited, but if all three are present, then performance is likely to be enhanced. The following sections are 
going to touch upon each one of the above-mentioned aspects of AMO theory in order to understand what motivates employees and how it can possibly translate into the company's overall performance.

\section{The benefits of unlocking employees' performance potential - case studies}

Companies with recognised and engaged employees are more likely to enjoy improved customer satisfaction, revenue growth, and greater customer retention. As demonstrated in a 2011 study by the Aberdeen Group, „The Engagement/Performance Equation”, best-in-class companies with formal recognition programs report three-and-a-half-times-greater customer retention and revenue growth. In short, engaged employees lead to happier, more loyal customers and better business.

As widely accepted by researchers in the field, how well the company is going to perform to a large extent depends on whether it can understand what motivates its employees. Still, as Michelle Pokorny (2013: 46) puts it, "today, engagement and motivation practices continue to be rooted in a dated belief that people, specifically employees, are motivated primarily out of rational self-interest", i.e. by financial incentives. In the 1920s Frederick Taylor (qtd. in Wilkinson 1998: 41), the father of scientific management, proposed a system based on worker compliance, where workers' job was limited to execution of tasks, while the brainpower was to be centred with management. As noted by Adrian Wilkinson (1998: 41), „,while scientific management was very successful in terms of boosting productivity, there was concern over the alienation of workers reflected in high labour turnover, absenteeism and conflict". Also, it seemed to yield better results in a manufacturing industry. Nowadays, the statistics indicate that the number of knowledge-based jobs requiring university education and expert skill sets will grow as developed economies continue to shift from manufacturing to service industries. This means that the latest highly educated population to enter the labor force, Generation Y (born 1977-94), are in great demand. Surveys and statistics depict Generation Y employees as more entrepreneurial, innovative, and self-interested than earlier generations in the 
labor force (Drake International 2006). This, unsurprisingly, requires a different approach than that put forward by Taylor a century ago.

Today, a new wave of respected thought leaders that include McKinsey, Harvard Business Review, PricewaterhouseCoopers and Aberdeen acknowledge the effectiveness and strategic business value of non-cash components. For instance, Aberdeen's annual Sales Performance Management Study of 2011 highlighted that best-in-class organizations - those which out-performed rivals across all major financial categories - are more than twice as likely as all other firms to provide noncash incentives. An April 2014 research study by the Aberdeen Group showcases the importance of non-cash incentives in both motivating and rewarding a more nuanced set of sales behaviours than those considered necessary a generation ago. This research report explores how this kind of total reward model, and associated recognition practices, can inspire peak sales performance results.

In Motivating People: Getting Beyond Money report by McKinsey (Dewhurst et al. 2009) the authors assert that it is time „to challenge the traditional management wisdom that it is money that really counts". Their research points to „noncash motivators - praise from immediate managers, leadership attention (for example, one-on-one conversations), and a chance to lead projects or task forces - as no less or even more effective motivators than the three highest-rated financial incentives: performance-based cash bonuses, increased base pay, and stock options". According to „McKinsey Quarterly” survey of June 2009 (qtd. in Dewhurst et al. 2009), these top three nonfinancial motivators play critical roles in making employees feel that their companies value them, take their well-being seriously, and strive to create opportunities for career growth. These themes recur constantly in most studies on ways to motivate and engage employees. This cost-effective approach offers business leaders a chance to more successfully reward talented employees by emphasising nonfinancial motivators rather than bonuses. Still, many organisations have not made more use of cost-effective nonfinancial motivators. The authors suggest that the reason for this may be twofold. First, the executives may still think that bonuses are the dominant incentive for most people, while being themselves equally influenced by other things. Another reason is probably that this nonfinancial approach to motivating employees is more time-consuming and requires more 
commitment from senior managers. They would have to leave their offices and talk to people. According to the authors, the lack of interaction between top managers and their people creates a detrimental void that saps employee engagement. At the same time, leadership attention belongs to the top three nonfinancial motivators as indicated by „McKinsey Quarterly” survey. For instance, it might be reinforced through gathering focus groups of talented managers within the company to generate ideas about how to create more value for the business while formulating corporate strategy every year (a case study of a global pharmaceutical company). As indicated by an HR director from a mining and basic-materials company ,one-on-one meetings between staff and leaders are hugely motivational - they make people feel valued during difficult times" (Dewhurst et al. 2009). Managers should, therefore, consider the accessibility issue strongly if they want to maintain a satisfied and gratified workforce. The report clearly shows that a chance to lead projects is a particularly powerful way of inspiring employees to make a strong contribution at a challenging time. Such opportunities also develop their leadership capabilities, with long-term benefits for the organisation. The employees themselves feel that they are a part of something bigger - the company's future. This is what makes even more surprising the fact that only half of the companies which took part in the survey use this tool of motivating employees on a regular basis.

Some far-thinking companies, though, are working hard to understand what motivates employees and act on their findings - and forward thinking managers know the well-being of the projects they manage rely on the abilities and talent of their people. They know they may be excellent at time management, organising, and delegating - but if they neglect the single and one of the most important managerial responsibilities - developing their people - all their other efforts are squandered altogether, taking a secondary position.

Sharon Thorne (prev. Fraser), currently a Managing Partner Global for Deloitte UK, was promoted to that position a couple of years ago. Previously, she was a Managing Partner for Talent at Deloitte, sitting on its UK Executive Board. Then, in one of the interviews (Trappe, Tullis 2011) she said that the very existence of her function and its status underlined how important people were to achieving Deloitte's strategy, i.e. being the preeminent professional services firm. As she put it: „to do that [author's note: 
to be the preeminent professional services firm] we have to have the best people working for us, to have them engaged, to retain them and to make them even better at doing what they're doing. It's really critical to our strategy and our agenda". The company's investment in its Human Resources seems to pay off. Due to their HR strategy, aligned with the firm's business strategy, Deloitte's has secured position of one of the leading firms in the accounting and consulting industry (so called The Big $4^{1}$ ), receiving numerous consecutive accolades for years. They have also won a number of awards over the last year. To name just a few, for the $17^{\text {th }}$ time since 1998, Deloitte has been named in „Fortune Magazine's” list of the „100 Best Companies to Work For". Vault's 2017 Accounting Rankings place Deloitte at No. 2 overall. According to Vault, it continues to rank highly in leadership, business outlook, and work/life balance, and ranks No. 1 for formal training. At Deloitte, 88 percent of employees say their workplace is great ${ }^{2}$. Table 1 presents the exact employee ratings, and Table 2 below shows what the employees actually say:

\section{Table 1. Deloitte - employee ratings}

\begin{tabular}{|l|c|}
\hline Great challenges & $97 \%$ \\
\hline Great atmosphere & $94 \%$ \\
\hline Great rewards & $92 \%$ \\
\hline Great pride & $95 \%$ \\
\hline Great communication & $95 \%$ \\
\hline Great bosses & $93 \%$ \\
\hline
\end{tabular}

Source: http://reviews.greatplacetowork.com/deloitte [10.02.2017].

\footnotetext{
${ }^{1}$ The Big 4 include Pricewaterhouse Coopers (PwC), Ernst \& Young (EY), Deloitte, and KPMG. They dominate the accounting and consulting industry in terms of their size, global reach, and reputation, among other factors.

${ }^{2}$ This review is based on 1067 employee surveys, with a $90 \%$ confidence level and a margin of error of \pm 2.49 . It was published on 16 Sep. 2016; http://reviews.greatplacetowork.com/deloitte [10.02.2017].
} 
Table 2. What employees say

\begin{tabular}{|l|c|}
\hline I am proud to tell others I work here & $94 \%$ \\
\hline I am given the resources and equipment to do my job & $93 \%$ \\
\hline People here are given a lot of responsibility & $93 \%$ \\
\hline I am offered training or development to further myself professionally & $92 \%$ \\
\hline Management is competent at running the business & $92 \%$ \\
\hline
\end{tabular}

Source: http://reviews.greatplacetowork.com/deloitte [10.02.2017].

The outcomes Deloitte consistently achieves over the years undeniably result from the company's talent management strategies. Thorne says that the talent strategies for their people in the UK involve recruitment and resourcing, people development, retention, looking after all kinds of appraisals, promotion processes, rewards and benefits. Attracting and getting the best people into the firm, both graduates and experienced professionals, is of paramount importance. Once hired, these people are given excellent development opportunities. It includes coaching and inspiring their people via on-the-job training provided by experts in the field - ,that's the way people learn the most from", Thorne adds. Therefore, development is critical to retaining talented staff. They must continue to get development and challenge in the work they do. Challenge is another aspect of Deloitte's talent management strategy. According to Thorne, Deloitte prides itself in having a high-performance culture, looking to recruit people who are looking for challenging work, e.g. serving clients who are involved in complex, difficult transactions within a complicated regulatory environment. This approach seems to translate into the company's sustainable competitive advantage and business outcomes, such as profitability, customer satisfaction and quality. Namely, through bringing highly motivated people into its business and giving them that sort of work, Deloitte is able to stand out in its industry because it has a broader span of services that it offers to clients, and so it is able to engage in more complex, and thus more expensive transactions. Thorne underscores the importance of a supportive environment in the process of employee development and growth within the 
organisation. This could be achieved via making people feel that they are individuals who have something unique to offer and that the company wants to have their input.

All of the mentioned ideas on how to attract talented recruits, and next keep them on board motivated, engaged and loyal to the company, seem to be compatible with those of Jim Goodnight's, the CEO at SAS - one of the world's biggest software maker with an unbroken chain of revenue growth and profitability that is unprecedented in the IT industry. A constant on Fortune's list of Best Companies to Work For in the US (in 2017, ranked as the $8^{\text {th }}$ among The 30 Best Workplaces in Technology ${ }^{3}$ ), SAS has long recognised the correlation between satisfied employees and business success. The tech industry has long been famed for its superior work environments and benefits - but there is a lot more than perks that goes into creating a workplace employees love. In an interview for „The Economist” (2007), Goodnight points out that it is not just the benefits that keep people at SAS - ,it's the challenge of the work”. A philosophy that Goodnight calls „Hire hard, manage open, fire hard" has paid off. SAS, in other words, takes a relaxed approach toward controls; but the culture is allergic to laziness. The average rate of staff turnover at SAS is around $4 \%$ a year, compared with around $20 \%$ in the software industry as a whole - and employee turnover is expensive. It has been calculated a few years ago that this alone saved SAS $\$ 85 \mathrm{~m}$ a year in recruitment and training costs. ,At SAS, we view our people as our greatest strength. A culture that fuels creativity and curiosity inspires great ideas and supports continued growth", said SAS Executive Vice President and Chief Human Resources Officer, Jenn Mann ${ }^{4}$. As one of the SAS employees said in the survey: „In contrast to other companies I've worked for, it's a comfortable work environment with minimal politics, and allows employees to give much greater focus to innovation, creativity, and detail".

The conclusion that could be drawn from these case studies is that the best leaders are able to inspire and empower innovation, as well as recognise and reward it. Micromanaged staff will not come up with innovative ideas - and that will

\footnotetext{
${ }^{3}$ To produce the list, ,Fortune” surveyed more than 42,000 employees of U.S. technology companies. It was published on 17 Jan. 2017. Retrieved from http://fortune.com/2017/01/17/best-workplaces-tech/ [14.02.2017].

${ }^{4}$ https://www.sas.com/en_us/news/press-releases/2017/february/sas-gptw-tech.html [15.02.2017].
} 
negatively affect the company's bottom line and competitive advantage in the long run. On the other hand, if employees feel valued and appreciated, they are much more likely to stay on board and contribute to the company's sustainable success.

The presented approaches fit well into House and Mitchell's (1974) PathGoal Theory of Leadership. Namely, both companies continually set challenging goals for their employees, thus showing belief in their staff's capabilities and potential to succeed. Also, they consider the needs of their employees via making their job more interesting and providing development and training opportunities, thereby increasing the employee's self-esteem. Both case studies encompass the three aspects of the AMO framework, i.e. the employees' abilities, motivation, and opportunities they get to make a contribution to the enterprise. As mentioned before, the AMO framework is the most popular theoretical perspective linking HRM and performance, and the examples discussed only go to show that working on these three aspects triggers tangible effects. The AMO framework provides a kind of structure of the best practice prescription for an organisation to remain healthy. The HRM practices mentioned by both Thorne and Goodnight have the most significant direct influence on employees' skills, motivation and empowerment. As observed by Jeffrey Gandz and Frederick Bird (1996: 383), „driven by competitive pressure, organisations are empowering employees to use their judgment, creativity and ideas in pursuit of enhanced organisational performance and both employee and shareholder satisfaction". Customers are demanding better products and services delivered in a fast, efficient and friendly manner, which can only be achieved through empowered employees and decision-making occurring at the nonmanagerial levels, as put forward by Philip Kotler and Paul Stonich (1991). Manoj Sharma and Gurvinder Kaur (2008) list autonomy and empowerment as two significant means in workplaces to instigate motivation.

The term „empowerment” can be used in a variety of ways. It may refer to arrangements that give workers more discretion over their own work. These arrangements typically allow workers greater say over the pace of work, the timing of when they begin and end work, and the degree of discretionary authority that they exercise. As Jim Goodnight once put it: „Creative people can be trusted to manage their own workloads. To support the creative process and meet the demands of 
family life, flexible work day guidelines encourage people to start each day at whatever time is best for them. Creativity can't be shoehorned between the hours of nine and five" (Harvard Business Review 2005). Outside the job basic work process itself is suggestion involvement, where workers make suggestions, but management decide whether to act on these; or more significant, where workers have some autonomy, addressing problems and implementing improvements themselves (Bowen, Lawler 1992, qtd. in Wilkinson 1998: 47). The company should encourage them to have their input, as it is done at Deloitte.

Gandz and Bird's (1996: 385) observation seems to neatly sum it all: „,where human resources are used to add maximum value instead of to check and doublecheck the work of others, where employees are charged with the responsibility to ensure that quality is built into the company's products and the business processes are continually improved to maximise customer value, business is doing what it is supposed to be doing". Employees simply must be given the opportunity to influence the basic processes within which they operate to make best use of their own potential contribution. Last but not least, for empowerment to be effective, employees must be given the training and development experiences necessary to maximise their added value, a view compatible with that of Sharon Thorne's, Managing Partner Global for Deloitte UK.

\section{Conclusions}

All in all, it seems that some HR practices translate into sustainable competitive advantage better than others, regardless of the industry. These preeminent practices include an open-minded management style, good communication, employee involvement, providing ample training/development opportunities and job challenge. It must be emphasised that these HR practices are more effective when combined, as shown in the case studies above. The presented real-life HR practices are compatible with their theoretical underpinnings. It turns out that the fresh approaches adopted by the analysed companies can be linked back to the seminal motivation theories and concepts relating HRM to performance. It seems that especially the application 
of AMO framework and Path-Goal Theory to workplace scenarios can yield good results, since the two theories capture employee needs particularly well, at the same time showing ways to meet these needs in order to achieve the goals of both the employee and the employer. The example of Deloitte has proven that HRM practices can be implemented as part of a well-thought-out HR strategy, thereby improving the company's efficiency and increasing its competitive advantage.

Still, HR processes often lag significantly behind business strategy processes at many companies. Consequently, firms are deficient in the human capital necessary to execute strategic plans, being unable to recruit talented people or losing them continuously. Some scholars argue that it is because the People component of the Triple Bottom Line has been explained too „externally”, pinpointing philanthropic initiatives that have nothing to do with the organisation's core business, while instead it should highlight the responsibility of the organisation towards its own employees (Kellerman 2010; De Prins 2011). Some forward-thinking companies are well aware that the positive impact of that will be felt on the bottom line, since consumers tend to choose companies which are treating their employees well. Studies indicate that aside from price and quality, how a company treats its employees is the most important factor for consumers when they make a decision to purchase a product (James 2001, qtd. in Gunning 2007). Therefore, companies should recognise more the power of influence of their employees over customers. Dawn James (2001) calls these employees ,living, breathing brand builders”. In the long run, the message they are getting across to customers can have a tremendous and lasting effect on the corporate image held in the mind of the company's multiple audiences, thus affecting the business's financial performance. James provides an example of British Airways whose stewardess spent most of the flight complaining about the working atmosphere, conditions and management style - so most of Herzberg's hygiene factors, which are likely to cause job dissatisfaction if deficient. Once jeopardised, the corporate image takes a lot of time (and money) to recover in the eyes of the public. That is why wise business leaders realise it is in their enlightened self-interest to inspire their employees, keeping them focused and feeling valued at all times. Employees' boosted creativity and loyalty translate into increased competitiveness of the company and enhanced corporate image held by 
the company's various publics. The end result is the business's sustainable development and long-term profitability.

Yet, according to a recent study by Joanna O'Riordan (2017), good HR practices in themselves are not enough to improve employee commitment or enhance the company's productivity. The organisation culture, which is strongly influenced by the approach to leadership and management in the organisation, is equally important. The positive, proactive attitude of line managers towards the implementation of HR policies should be coupled with their efforts to involve staff and respond to their suggestions to make a real difference to employees' attitudes, thus increasing employee motivation and productivity. As O'Riordan (2017) aptly puts it: „It is not something that can be legislated for because it is a behaviour rather than a duty. It is strongly linked to the way that the line managers are themselves managed and to the wider values and culture of the organisation".

\section{References}

Aberdeen Group (2011), The engagement/performance equation, White paper.

Aberdeen Group (2011), Sales performance management, White paper.

Aberdeen Group (2014), Incenting success. Best-in-class sales management, White paper.

Appelbaum E., Bailey T., Berg P., Kalleberg A. (2000), Manufacturing advantage. Why high-performance work systems pay off, Cornell University Press, Ithaca NY.

Becker B., Gerhart, B. (1996), The impact of human resource management on organizational performance. Progress and prospects, „Academy of Management Journal”, vol. 39 no. 4, pp. 779-801.

Bowen D., Lawler E. (1992), The empowerment of service workers. Why, how and when?, „Sloan Management Review”, vol. 33 no. 3, pp. 31-39.

Colbert B. (2004), The complex resource-based view. Implications for theory and practice in strategic human resource management, „Academy of Management Review”, vol. 29 no. 3, pp. 341-358. 
De Prins P. (2011). Duurzaam HRM. Synthetische academische introductie, cited by: Rompa I. (2011), Explorative research on Sustainable Human Resource Management, http://www.innovatiefinwerk.nl/sites/innovatiefinwerk.nl/files/field/bijlage/sustainable_hrm. pdf [31.01.2017].

Dewhurst M., Guthridge M., Mohr E. (2009), Motivating people. Getting beyond money, „McKinsey Quarterly”, November, http://www.mckinsey.com/businessfunctions/organization/our-insights/motivating-people-getting-beyond-money [03.01.2017]

Drake International (2006), Generation Y. Attracting, engaging and leading a new generation at work, White paper.

Gandz J., Bird F. (1996), The ethics of empowerment, „Journal of Business Ethics”, vol. 15 no. 4 , pp. 383-392.

Gunning E. (2007), Public relations. A practical approach, 2nd ed., Gill \& Macmillan, Dublin.

Harvard Business Review (2005), Managing for creativity, July-August Issue, https://hbr.org/2005/07/managing-for-creativity [10.02.2017].

Herzberg F., Mausner B., Snyderman B. (1959), The motivation to work, 2nd ed., John Wiley \& Sons, New York.

House R. (1971), A path-goal theory of leader effectiveness, „Administrative Science Quarterly", vol. 16 no. 3, pp. 321-339.

House R., Mitchell T. (1974), Path-goal theory of leadership, „Contemporary Business”, vol. 3, pp. 81-98.

James D. (2001), Living, breathing brand builders, „IPRA Frontline Magazine”, December.

Jiang K., Lepak D., Han K., Hong Y., Kim A., Winkler A. (2012a), Clarifying the contrast of human resource systems, „Human Resource Management Review”, vol. 22 no. 2, pp. 73-85.

Jiang K., Lepak D., Hu J., Baer J. (2012b), How does human resource management influence organizational outcomes? A meta-analytic investigation of mediating mechanisms, „Academy of Management Journal”, vol. 55 no. 6, pp. 1264-1294.

Kellerman A. (2010), Duurzaam Leiderschap. De sleutel voor duurzaamheid ligt bij HRM!, „Leadership”, vol. 3, pp. 18-21, cited in: Rompa I. (2011) Explorative research on sustainable human resource management, http://www.innovatiefinwerk.nl/sites/innovatiefinwerk.nl/files/field/bijlage/sustainable_hrm. pdf [31.01.2017]. 
Kotler P., Stonich P. (1991), Turbo marketing through time compression, „, The Journal of Business Strategy", vol. 12 no. 5, pp. 24-29.

Maslow A. (1943), A theory of human motivation, „Psychological Review”, vol. 50 no. 4, pp. 370-396.

McGregor D. (1960), The human side of enterprise, McGraw-Hill, New York.

Mucha R. (2004), The art and science of talent management, „Organization Development Journal", vol. 22 no. 4, pp. 22-30.

O'Riordan J. (2017), The practice of human resource management. State of the public service series, Institute of Public Administration Research Paper, no. 20 (July), IPA, Dublin, https://www.ipa.ie/_fileUpload/Documents/THE_PRACTICE_OF_HRM.pdf [06.04.2018].

Pokorny M. (2013), Getting to know your employees and what motivates them, „Employment Relations Today (Wiley)”, vol. 39 no. 4, pp. 45-52.

Purcell J., Kinnie N., Hutchinson S., Rayton B., Swart N. (2003), Understanding the people and performance link. Unlocking the black box, Research Report, CIPD, London.

Rompa I. (2011) Explorative research on sustainable human resource management, http://www.innovatiefinwerk.nl/sites/innovatiefinwerk.nl/files/field/bijlage/sustainable_hrm. pdf [31.01.2017].

Sharma M., Kaur G. (2008), Employee empowerment. A conceptual analysis, „Journal of Global Business Issues”, vol. 2 no. 2, pp. 7-12.

The Economist (2007), Doing well by being rather nice, 29 November, http://www.economist.com/node/10208507 [15.12.2016].

Theriou G., Chatzoglou P. (2009), Exploring the best HRM practices-performance relationship. An empirical approach, „Journal of Workplace Learning”, vol. 21 no. 8, pp. 614-646.

Trappe T., Tullis G. (2011), Intelligent business, 1st ed. [audio CD], Pearson Education Limited, London.

Wilkinson A. (1998), Empowerment. Theory and practice, „Personnel Review”, vol. 27 no. 1, pp. 40-56.

Wright P., Gardner T., Moynihan L. (2003), The impact of HR practices on the performance of business units, „Human Resource Management Journal”, vol. 13 no. 3, pp. 21-36. 